\title{
Sensor module for testing magnetometric borehole inclinometers under field conditions
}

\author{
Anatoly Gormakov ${ }^{1, *}$, Mikhail Kharitonov ${ }^{2}$, and Andrey Prygov ${ }^{1}$ \\ ${ }^{1}$ National Research Tomsk Polytechnic University, 634050 Tomsk, Russia \\ ${ }^{2}$ Research and Development Centre 'Polyus', 634050 Tomsk, Russia
}

\begin{abstract}
The paper presents the testing procedure and the test unit for borehole inclinometers using a reference system of orientation incorporated in the sensor module. Computational algorithms are developed for azimuth, zenith and apsidal angles. The estimated error is obtained for the detection of zenith angles. The sensor module uses the Honeywell HMS1053, a digital resistance magnetometer and the Colibrys MS9000 accelerometer. The size and weight of the test unit are rather small that provides its easy transportation. The test unit is universal as it can be used for inclinometers with different casing diameters. The cost of the test unit is much lower than that of the stationary one. Easy servicing reduces the labor content during the inclinometer in situ testing.
\end{abstract}

\section{Introduction}

The outer space exploration begins with the first stages of launch site construction and ends with the borehole drilling aimed at the investigation of the structure and composition of the surface and deep layers of cosmic bodies [1].

The metrological support of the inclinometer survey instruments is provided by the metrological installations for calibration and testing borehole inclinometers of the types USI-2, UPI-1, UKI-2, UNP-3 and some others [2-6]. These installations can be used only in steady-state conditions of the inclinometer manufacturer or in laboratories of geophysical companies. An operational test of inclinometers has not been provided in situ until present time. In [7-8] the authors proposed the improved testing procedure and the test unit for borehole inclinometers.

\section{Test unit and procedure for testing borehole inclinometers}

The procedure for testing borehole orientation system is presented in Figure 1. The sensor module 5 which incorporates the reference orientation system is attached to the inclinometer casing 1 using the frame (prism) 2, brackets 3, and pressure screw 4.

The sensor module allows mounting inclinometers of different casing diameters. The sensor module is mounted to the inclinometer casing via the prismatic surface of the frame

\footnotetext{
* Corresponding author: gormakov@,tpu.ru
} 
2. This construction provides the alignment of sensitivity axes of the sensor module 5 and the inclinometer casing 1 . An arbitrary spatial attitude is then given to the inclinometer casing. The signals from the inclinometer casing and the sensor module enter the data collection units 6 and 7, respectively. The obtained results are interpreted by the computer 8 and displayed on the monitor, so the performance of the sensor module can be then evaluated. In case the sensor module matches the accuracy requirements, it is put into operation. Otherwise, it should be sent to a repair facility.

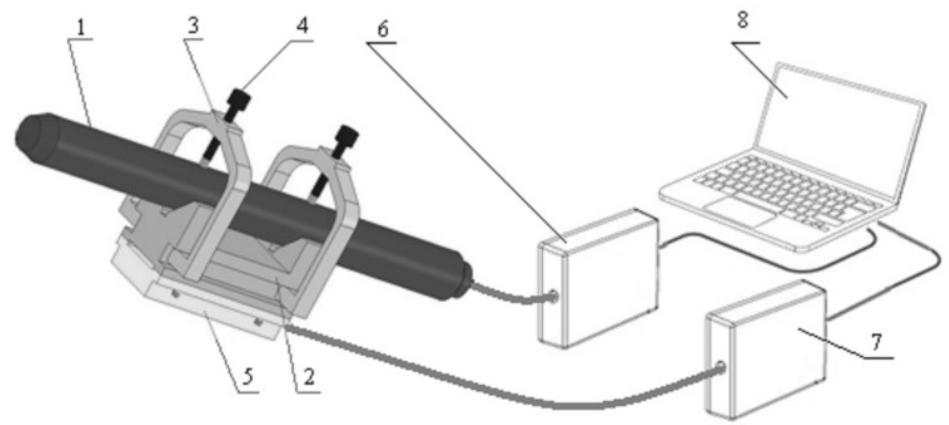

Fig. 1. Schematic drawing of inclinometer test unit using the sensor module.

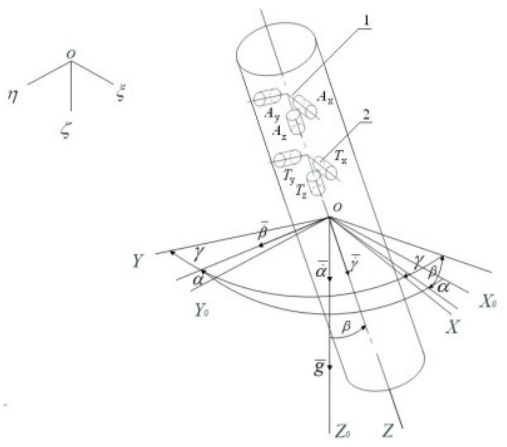

Fig. 2. Sensor module of the reference system of orientation.

In the related references [11-14], it was observed that in years ahead, the borehole orientation systems based on MEMS [15] accelerometers and resistance magnetometers will be widely used for bottom-hole inclinometers thanks to their operability under the vibration, shaking and high-temperature conditions.

The proposed sensor module uses the Honeywell HMS1053, a digital resistance magnetometer [16-17] and the Colibrys MS9000 accelerometer [18].

\section{Sensor module configuration}

The general configuration of the sensor module is presented in Figure 2. The accelerometer unit $l\left(A_{x}, A_{y}, A_{z}\right)$ and the magnetometer unit $2\left(T_{x}, T_{y}, T_{z}\right)$ are placed along each of the axes of $O X Y Z$ coordinate system connected to the sensor module housing. The linear accelerometers $A_{x}, A_{y}, A_{z}$ measure the trimetric projection of apparent accelerations $a_{x}, a_{y}$, $a_{z}$ which is connected to the sensor module housing. 
According to Figure 2, the axis $O \zeta$ of the reference coordinate system $O \xi \eta \zeta$ is directed downward, while the axes $O \xi$ and $O \eta$ are horizontal, $O \xi$ being lied in a plane of the astronomical meridian and directed northward. The axes of $O X_{0} Y_{0} Z_{0}$ coordinate system always originating from the point $O$ of the test unit are parallel to the respective axes of $O \xi \eta \zeta$ coordinate system.

In order to obtain the computational algorithms for azimuth angle, let us consider three sequential rotations of $O X Y Z$ coordinate system relative to $O X_{0} Y_{0} Z_{0}$ coordinate system, respectively at azimuth angle $\alpha$, zenith angle $\beta$, and apsidal angle $\gamma$.

The vector components for gravitational acceleration $g$ on the axis of $O X Y Z$ coordinate system can obtained from Eq. (1).

$$
\left.\begin{array}{l}
a_{x}=-g \cdot \sin \beta \cdot \cos \gamma \\
a_{y}=g \cdot \sin \beta \cdot \sin \gamma
\end{array}\right\}
$$

Using the system of equations (1), the main value of zenith angle $\beta^{*}$ is written as

$$
\beta^{*}=\arcsin \sqrt{\frac{a_{x}^{2}+a_{y}^{2}}{g^{2}}},
$$

the apsidal angle $\gamma$ can be obtained from

$$
\gamma=-\operatorname{arctg} \frac{a_{y}}{a_{x}}
$$

and azimuth angle $\alpha$ is calculated from

$$
\alpha=\operatorname{arctg}\left(\frac{T_{x} \cdot \sin \gamma-T_{y} \cdot \cos \gamma}{T_{x} \cdot \cos \beta \cdot \cos \gamma+T_{y} \cdot \cos \beta \cdot \sin \gamma-T_{z} \cdot \sin \beta}\right),
$$

where $T_{x}, T_{y}, T_{z}$ are the signals from the respective magnetoresistive sensors.

\section{Error estimation for zenith angle detection}

The error estimation of the sensor module when measuring the zenith angle is provided by the theorem for functions of several variables. Thus, the error is found from where $\Delta a_{x}, \Delta a_{y}$ are the measurement errors of accelerometers placed on $X$ - and $Y$-axes; $\Delta g$ is the error of gravitational acceleration.

$$
\begin{aligned}
& \Delta \beta=\left(\left|\frac{a_{x}}{g^{2} \cdot \sqrt{\frac{a_{x}^{2}+a_{y}^{2}}{g^{2}}} \cdot \sqrt{1-\frac{a_{x}^{2}+a_{y}^{2}}{g^{2}}}}\right| \cdot\left|\Delta a_{x}\right|\right)+\left(\left|\frac{a_{x}}{g^{2} \cdot \sqrt{\frac{a_{x}^{2}+a_{y}^{2}}{g^{2}}} \cdot \sqrt{1-\frac{a_{x}^{2}+a_{y}^{2}}{g^{2}}}}\right| \cdot\left|\Delta a_{y}\right|\right)+ \\
& +\left(\left|\frac{a_{x}}{g^{3} \cdot \sqrt{\frac{a_{x}^{2}+a_{y}^{2}}{g^{2}}} \cdot \sqrt{1-\frac{a_{x}^{2}+a_{y}^{2}}{g^{2}}}}\right| \cdot|\Delta g|\right)
\end{aligned}
$$


The error calculations showed that the zenith angle error did not ecxeed $0,05 \%$ at zenith angles ranging from $0^{\circ}$ to $85^{\circ}$ and all possible values of apsidal angle $\gamma$. At zenith angle $\beta$ bing close to $90^{\circ}$, the error is $0,17 \%$. It should be noted that the obtained errors are maximum errors which, however, can hardly be expected to appear.

\section{Conclusions}

The research investigations resulted in the construction of the flow sheet of the reference borehole orientation system; selection of sensor elements; development of computational algorithms for orientation angles; and estimation of measurement errors for zenith angle. The proposed test unit can be used for testing borehole inclinometers in the field conditions. The use of the Honeywell HMS1053, a digital resistance magnetometer and the Colibrys MS9000 accelerometers will allow the researchers to implement a safe structure of the sensor module possessing the small size and weight.

\section{References}

1. Burenie v kosmose, URL : http://byrim.com/burenie/13.html

2. E.V. Golodnykh, V.N. Borikov, SIBCON, 6693635 (2013)

3. Z.G. Gareishin, Concepts of assembling metrological setups of borehole electronics orientation (Ural-Geo Centre, Ufa, 2006)

4. A.N. Golikov, A.N. Gormakov, Kontrol'. Diagnostika. Spec. issue, 42 (2011) (in Russian)

5. Ustanovka UNP-3 KSVSh, URL: www.oskbp.ru/index.php?id=19 (in Russian)

6. Gyroscopic inclinometr «IGM33/42, URL: www.trend.miass.ru/prod02_e.htm

7. A.N. Gormakov and et al, RF Patent (2010) (in Russian)

8. A.N. Gormakov, I.A. Ul'yanov, V.G. Tkachev, Vest. Nauki Sibiri. 2, 101 (2014) (in Russian)

9. J. Bojja and et al, IEEE Sens. J. 16, 8, (2016)

10. V.S. Volkova, V.I. Kopytov, KORUS 2001, 29 (2001)

11. V.S. Ivanova, MTT 2002, 59 (2002)

12. Solod-state MEMS inclinometer, URL: www.radiant.su/files/images/sq/sq-si$360 \mathrm{da} \% 20$ (sq-six).pdf

13. Digital inclinometer system, URL: www.rstinstruments.com/Digital\% 20MEMS\% 20Inclinometer.html

14. Arduino inclinometer, URL: http://appsmagz.us/arduino/arduino-inclinometer

15. P. Baranov, and et al, IMEKO (2016)

16. A. Borisov, Comp. \& Technol., 7, 56 (2006)

17. 1,2 and 3 axis magnatic sensors, URL: www.electronshik.ru/pdf/pdf/h/ hmc105x.pdf

18. Yu. Ponomarev, Comp. \& Technol., 10, 34 (2015) 